\title{
Using the Photoinduced Reversible Refractive-index Change of an Azobenzene Co-polymer to Reconfigure an Optical Bragg Grating
}

Richard M Parker, ${ }^{a, b}$ James C Gates, ${ }^{b}$ Helen L Rogers,${ }^{b}$ Peter G R Smith,${ }^{b}$ and Martin C Grossel ${ }^{* a}$

${ }_{5}^{a}$ School of Chemistry, University of Southampton, Southampton UK SO17 1BJ. E-mail: mcg1@soton.ac.uk.

${ }^{b}$ Optoelectronics Research Centre, University of Southampton, Southampton, UK

Please cite this paper as:

J. Mater. Chem., 2010,20, $9118-9125$

The publisher's version of this paper is available here:

15 http://dox.doi.org/10.1039/C0JM01334J

Related articles by Dr Martin Grossel can be found below:

R.M. Parker, J.C. Gates, M.C. Grossel and P.G.R. Smith, In vacuo measurement of the sensitivity limit of planar Bragg grating sensors for monolayer detection, Appl. Phys. Lett. 2009, 95, 173306. (doi:10.10631/1.3257727)

R.M. Parker, J.C. Gates, M.C. Grossel and P.G.R. Smith, A Temperature Insensitive Bragg

Grating Sensor - Using orthogonal polar polarisation modes for in situ temperature

compensation, Sensors and Actuators, 2010. B145, 428-432.

(doi:10.1016/j.snb.2009.12.059)

R.M. Parker, J.C. Gates, H.L. Rogers, P.G.R. Smith and M.C. Grossel, An integrated reconfigurable Bragg grating utilising a photoresponsive co-polymer, J. Mater. Chem. 2010, 20, 9118-9125. (doi: 10.1039/c0jm01334j

N. Alderman, L. Danos, M.C. Grossel, and T. Markvart. Large surface photovoltages observed at methylterminated silicon surfaces synthesized through a two-step chlorination-alkylation method. RSC Advances, 2012, 2, 7669-7672 (DOI: 10.1039/C2RA20465G)

R.M. Parker, J.C. Gates, D.J. Wales. P.G.R. Smith and M.C. Grossel. An investigation into Dispersion upon Switching between Solvents within a Microfluidic System using a Chemical Resistant Integrated Optical Refractive Index Sensor, Lab Chip, 2013, 13 (3), 377-385 (DOI: 10.1039/C2LC41124E) 


\section{Using the Photoinduced Reversible Refractive-index Change of an Azobenzene Co-polymer to Reconfigure an Optical Bragg Grating}

\section{Richard M Parker, ${ }^{a, b}$ James C Gates, ${ }^{b}$ Helen L Rogers, ${ }^{b}$ Peter G R Smith, ${ }^{b}$ and Martin C Grosse ${ }^{* a}$}

$5_{5}^{a}$ School of Chemistry, University of Southampton, Southampton, UK, Tel: +44 (0) 2380 293153, E-mail: mcg1@ soton.ac.uk.

${ }^{b}$ Optoelectronics Research Centre, University of Southampton, Southampton, UK.

\section{Table of Contents Summary and Graphic:}

When a photo-switchable material in which azobenzene units are attached to a methacrylate copolymer, is combined with a direct UV-written silica-on-silicon Bragg grating a novel optical ${ }_{10}$ device is produced that undergoes repeated, reversible refractive index changes at telecomm wavelengths.

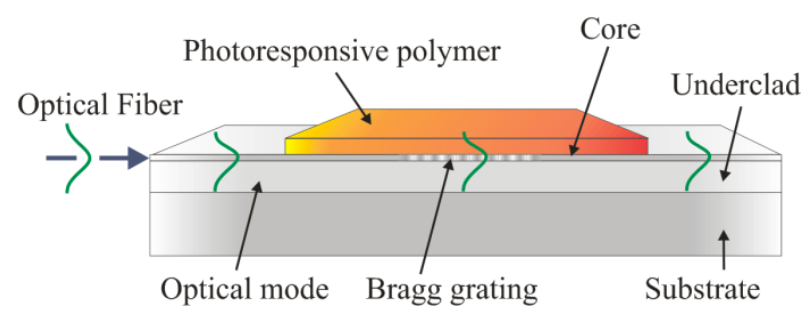




\title{
Using the Photoinduced Reversible Refractive-index Change of an Azobenzene Co-polymer to Reconfigure an Optical Bragg Grating
}

\author{
Richard M Parker, ${ }^{a, b}$ James C Gates, ${ }^{b}$ Helen L Rogers, ${ }^{b}$ Peter G R Smith, ${ }^{b}$ and Martin C Grossel ${ }^{* a}$ \\ ${ }^{a}$ School of Chemistry, University of Southampton, Southampton, UK, Tel: +44 (0) 2380 593153, E-mail: mcg1@ soton.ac.uk. \\ ${ }^{b}$ Optoelectronics Research Centre, University of Southampton, Southampton, UK.
}

\author{
Received (in $X X X, X X X) X$ th $X X X X X X X X X 200 X$, Accepted Xth $X X X X X X X X X 200 X$ \\ First published on the web Xth $X X X X X X X X X 200 X$ \\ ${ }_{10}$ DOI: 10.1039/b000000x
}

A photoactive material has been synthesised in which azobenzene units are attached to a methyl methracylate / 2-hydroxyethyl methacrylate co-polymer and shows repeated photoresponsive switching upon irradiation at $365 \mathrm{~nm}$ and $254 \mathrm{~nm}$ with long term thermal stability. In combination with a direct UV-written silica-on-silicon Bragg grating, this has been used to fabricate a prototype 15 optical device which undergoes reversible refractive index changes at telecomm wavelengths. The $63 \mathrm{GHz}$ tuning response demonstrated by this device has potential applicability for reconfigurable dispersion compensation for use in optical networks.

\section{Introduction}

Organic polymers have found many applications in electronic 20 and optical devices. They offer process compatibility, flexibility in design, and the ability for integration of electronic and optoelectronic functions. Numerous polymer systems have been developed for optical applications, with the key requirement imposed for such materials being 25 transparency. Much interest has focused on acrylic polymers because of their well-known optical properties and good filmforming capability ${ }^{1}$ Furthermore, azobenzene-based polymers can act as photosensitive, nonlinear optical, or photorefractive materials with ever increasing fields of 30 application, including: programmable optical interconnects; electro-optic modulation; coherent image amplification; and holographic storage ${ }^{2}$.

The simple azobenzene motif can undergo reversible photoisomerisation allowing the photoactive units to be 35 optically pumped almost exclusively from the trans to the cis isomeric state upon exposure to ultraviolet light. Upon isomerisation there is a change in the polarisability of the azobenzene molecule, resulting in a change in refractive index. It has been reported $^{3}$ that the trans-isomer is 40 thermodynamically more stable by $50 \mathrm{~kJ} \mathrm{~mol}^{-1}$, while the barrier to photoisomerisation is approximately $200 \mathrm{~kJ} \mathrm{~mol}^{-1}$. The cis-isomer will slowly relax thermally back to the transisomer in the absence of light, but the activation barrier for this process is $96 \mathrm{~kJ} \mathrm{~mol}^{-1}$ in solution or $130 \mathrm{~kJ} \mathrm{~mol}^{-1}$ in the 45 solid state. The corresponding half-life of the cis-isomer is in the order of a day at room temperature.

Reconfigurable optical devices are of great interest for telecomm applications; including dispersion compensation and tunable add-drop multiplexers. Bragg gratings - optical 50 components that reflect at one particular wavelength of light and transmit all others - are important elements in such systems. For these applications, optical Bragg grating structures need to be reconfigurable with both fine control and wide tunability of the Bragg wavelength desired. Previous 55 approaches to this problem were to incorporate a degree of reconfigurability into existing Bragg devices through tuning of the refractive index by temperature ${ }^{4}$, piezoelectric $^{5}$, magnetostrictive ${ }^{6}$, or mechanically induced strain $^{7}$. With some exceptions, these all require a continual supply of 60 electrical power to maintain the altered wavelength.

Direct UV writing can be used to fabricate a wide range of integrated optical devices. This technique is based on the localised refractive index increase of a photosensitive planar glass layer through exposure to a tightly focused UV beam. ${ }_{65}$ The translation of this beam relative to a suitable substrate allows for the definition of two-dimensional waveguide structures, without photolithographic or subsequent processing ${ }^{8,9}$. Furthermore, Bragg gratings can be written directly into the substrate by direct grating writing. This is 70 achieved through splitting of the single beam into two interfering beams. Controlled modulation of this interference pattern allows for both the grating and the channel structure to be formed simultaneously using the same photosensitive material response ${ }^{10}$.

75 Barley $^{11}$ has reported an example of a siloxane-based polymer functionalized with an azobenzene derivative. This had a refractive index compatible with that of telecommunication grade devices $(\sim 1.46)$, usefully lower than that seen in other active materials such as liquid crystals. The 80 polymer contained only 5\% azobenzene units but still exhibited a change in refractive index of $3.5 \times 10^{-3}$. Incorporation of such a polymer into an integrated Bragg grating device would allow for a latched reconfiguration of the Bragg wavelength without the need for continual electrical 85 input by photo-switching between isomeric states.

We present here a proof of concept for a reconfigurable 



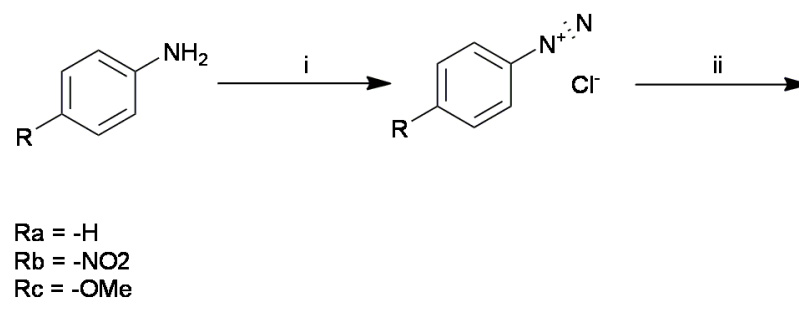<smiles>[R]c1ccc(N=Nc2ccc(OCC(=O)O)cc2)cc1</smiles><smiles>[R]c1ccc(N=Nc2ccc(OCC(=O)OCC)cc2)cc1</smiles>

Scheme 1 The synthetic pathway towards a family of para substituted azobenzene derivatives; i) $\mathrm{NaNO}, \mathrm{HCl},<5^{\circ} \mathrm{C}$, ii) phenol, $<5{ }^{\circ} \mathrm{C}$, iii) ethyl bromoacetate, $\mathrm{K} 2 \mathrm{CO} 3$, $\mathrm{NaI}$ acetone, iv) $\mathrm{NaOH}$, ethanol.

Bragg grating filter using the refractive-index change produced by photo-induced isomerisation of an azobenzene ${ }_{5}$ functionalized methacrylate co-polymer. The device may be optically switched between two states and exhibits multi-hour stability.

\section{Results and Discussion}

2.1. Investigation of the effect of para substituents on the 10 absorption spectrum upon isomerisation.

The absorption spectrum of the azobenzene unit contains an intense absorption peak corresponding to the $\pi-\pi^{*}$ electronic transition of the trans-isomer and a weak peak that originates from the weak $\mathrm{n}-\pi^{*}$ electronic transition of the $c i s$-isomer ${ }^{12}$.

${ }_{15}$ The change in absorption upon photoisomerisation is directly related to the change in refractive-index. This is defined by the Kramers-Kronig relationship, whereby a larger change in absorption implies a greater change in refractive-index. This allows for the change in refractive-index to be predicted from 20 the magnitude of the change in the absorbance spectrum. To investigate the change in refractive-index upon photoisomerisation, a family of para-substituted 4phenylazophenoxyacetic acid derivatives was synthesized, as shown in Scheme 1.

25 The relative absorbance of the two isomers is dependent on
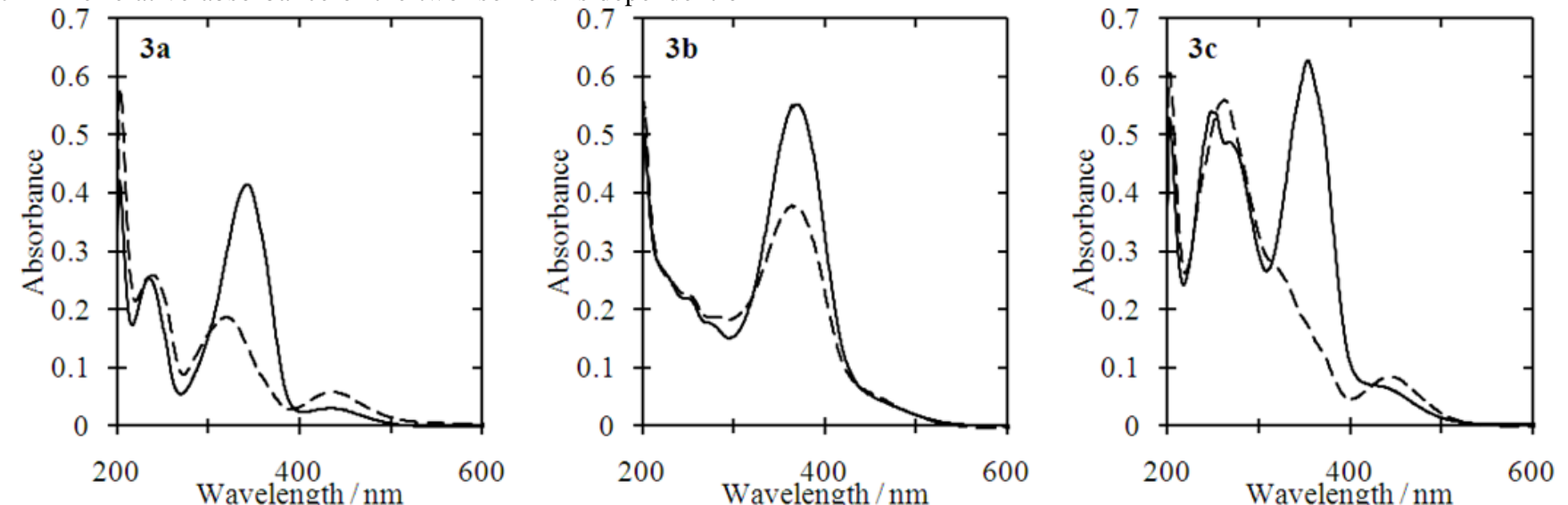

50 Fig. 1 The absorption spectra for cis (dashed) and trans (solid) para substituted azobenzene derivatives: $c i s-3 \mathbf{a}\left(\lambda_{\max }=320.5,450.5 \mathrm{~nm}\right)$ and trans-3a $\left(\lambda_{\max }\right.$ the electron density within the conjugated azobenzene motif. Upon photoisomerisation, the azobenzene passes from the planar trans-isomer to the twisted cis-isomer in which the phenyl rings are rotated out of alignment to avoid steric 30 interference. This results in reduced conjugation in the cisisomer. Increasing electron density within the conjugated system exaggerates this difference in orbital alignment between the fully conjugated and partially conjugated states. This results in significant changes in the UV-visible spectrum 35 of the electron rich $p$-methoxy derivative, $\mathbf{3 c}$, and the electron deficient $p$-nitro derivative, $\mathbf{3 b}$ (Fig.1).

The solution phase UV-visible absorption spectra for compounds 3a, 3b and 3c are shown in Figure 1, for a concentration of $2.5 \times 10^{-5} \mathrm{~mol} \mathrm{dm}^{-3}$ in methanol. For all 40 three compounds, exposing the trans-isomer to ultraviolet light, at $365 \mathrm{~nm}$, induces photoisomerisation to the cis-isomer with a reduction of the peak at $340-370 \mathrm{~nm}$. For 3c, the strong peak at $356 \mathrm{~nm}$ undergoes complete loss while simultaneously a second peak, corresponding to the cis45 isomer, is observed to form at $444 \mathrm{~nm}$. A similar transition is observed for 3a, albeit to a lesser extent, with only a decrease in the absorption peak at $342 \mathrm{~nm}$. In contrast, the $p$-nitrofunctionalized derivative $3 \mathbf{b}$ shows a much less marked spectral change, with the formation of the new peak at






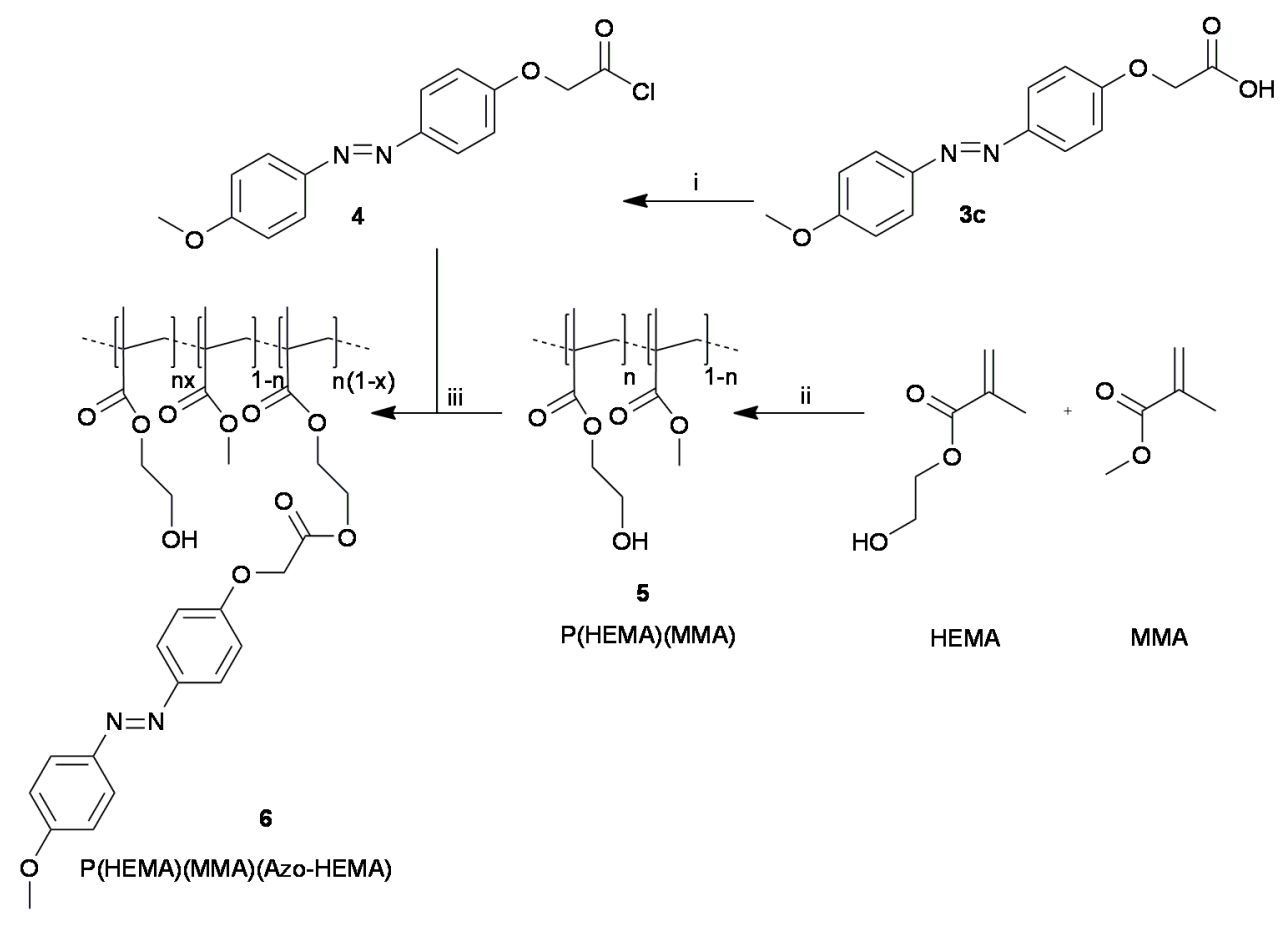

Scheme 2 The synthetic pathway towards an azobenzene functionalised methracylate co-polymer; i) thionyl chloride, reflux, ii) AIBN, methanol, iii) triethylamine, 2-butanone.

higher wavelength not being observed.

While $\mathbf{3 b}$ is the most polar of the three compounds, it has 5 the lowest electron density within the conjugated system and this is seen with the smallest transition in the absorption spectrum upon photoisomerisation. In contrast $\mathbf{3 c}$ has two electron-donating groups on the periphery of the azobenzene core and this correlates to the most marked change in the UV 10 visible absorption spectrum.

\subsection{Preparation and characterization of an azobenzene functionalized methacrylate co-polymer.}

Methyl methacrylate derived co-polymers, such as poly(methyl methacrylate / 2-hydroxyethyl methacrylate),

${ }_{15} \mathrm{P}$ (MMA)(HEMA), have suitable refractive-indices for use in waveguide systems (refractive-index of $\mathrm{P}(\mathrm{MMA})(\mathrm{HEMA})=$ 1.497 - 1.516, depending on the MMA:HEMA composition $^{12}$ ), while the pendant hydroxyl groups in the latter component allow further functionalisation. The present 20 work describes the radical copolymerization of methyl methacrylate and 2-hydroxyethyl methacrylate to form a 51:49 P(MMA)(HEMA) co-polymer, 5, into which $4.8 \%$ paramethoxy azobenzene units, $\mathbf{4}$, were incorporated along the polymer backbone, 6 (Scheme 2). The molecular weight $\left(\mathrm{M}_{\mathrm{w}}\right.$, 25 expressed as 'PMMA equivalent' molecular weight) of $\mathbf{5}$ was determined to be ca. 190,500 by GPC (gel permeation chromatography), increasing to 301,500 after attachment of the pendant azobenzene arms, 6.

The UV-visible absorption spectrum for the co-polymer 30 film, 6, spun onto a silica substrate, shows that there is an intense absorption peak at $361 \mathrm{~nm}$ (Fig. 2) corresponding to the trans-isomer and a weak peak at $451 \mathrm{~nm}$ which originates from the cis-isomer. When the film is irradiated by ultraviolet light at $365 \mathrm{~nm}$, the azobenzene units within the co-polymer
35 undergo trans-cis isomerisation; indicated by the decline of the strong trans and increase of the weak cis absorption band. After twelve minutes, no further change was detected in the adsorption spectrum, while the reverse isomerisation from $\mathrm{cis}$ to trans took fifteen minutes.

\section{${ }_{40}$ 2.3. A reconfigurable Optical Bragg grating.}

A silica-on-silicon sample was fabricated, where the core layer was doped with germanium to provide photosensitivity. On exposure to a pair of interferometric UV laser beams $(\lambda=$ $244 \mathrm{~nm}$ ) the refractive-index of the germanium-doped glass ${ }_{45}$ locally increased, forming an optical waveguide, furthermore modulation of the beam intensity allowed for four Bragg gratings of different periods to be simultaneously written

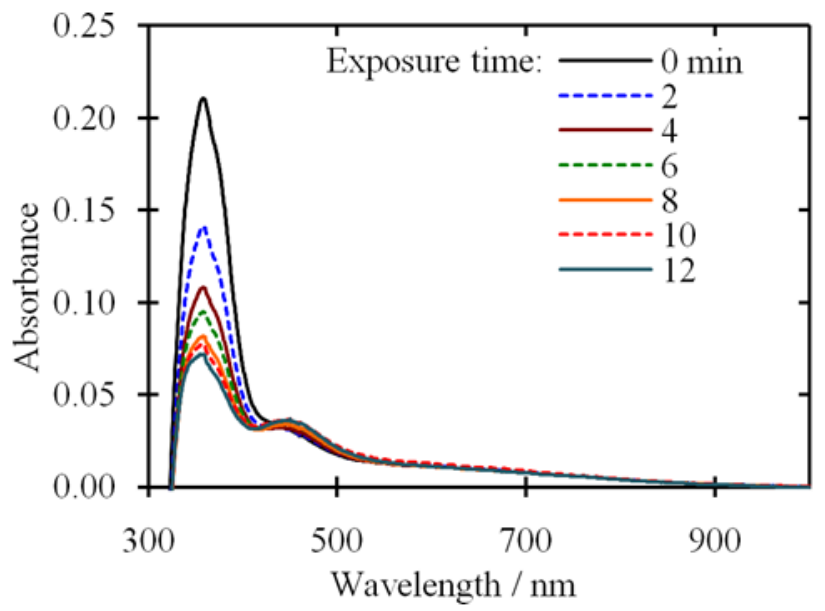

Fig. 2 Time-lapse UV-vis spectra showing the trans-cis transition of a $191 \mathrm{~nm}$ thick $p$-methoxy azobenzene containing methacrylate co-polymer 50 film, on exposure to ultraviolet light $(354 \mathrm{~nm})$ over 12 minutes. 


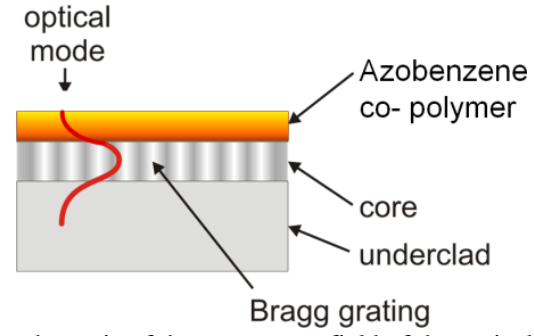

Fig. 3 A schematic of the evanescent field of the optical waveguide penetrating into the photo-responsive azobenzene co-polymer film.

along the channel waveguide. The reflectance spectrum in the visible and near-infrared regions were analysed remotely by 5 commercial telecoms test and measurement equipment via a fibre pigtail, allowing for the sub-picometer resolution of the peak Bragg wavelengths ${ }^{10}$.

Unlike an optical fibre, no overclad layer was present allowing the evanescent optical field to penetrate up from the 10 waveguide surface. The exposed evanescent field caused the optical mode to be sensitive to the refractive-index of its surroundings and the corresponding shift in peak wavelength of the Bragg spectrum was used to interrogate changes in this environment. Onto this surface a $413 \pm 27 \mathrm{~nm}$ thick film of the 15 azobenzene-functionalized co-polymer, 6, was spun (Fig. 3). The presence of the film and its ability to undergo photoisomerisation was confirmed by diffuse-reflectance UVvisible spectroscopy.

Analysis initially focused on the interrogation of the Bragg 20 responses around $780 \mathrm{~nm}$, spectrally near to the absorption feature. At this wavelength, the co-polymer induced high optical loss into the waveguide device, with almost total loss of the optical mode after travelling only $20 \mathrm{~mm}$ along the polymer-coated waveguide. Despite the loss, we were able to 25 interrogate the reflectance spectrum of two Bragg gratings within the waveguide. The sample was alternately exposed to ultraviolet light at 365 and $254 \mathrm{~nm}$, thermal changes being monitored by a thermocouple in thermal contact with the optical device. The Bragg response demonstrated 30 reproducible wavelength tuning between the two isomeric states, separated by $35 \mathrm{pm}$ - a well-resolved transition that corresponds to $17 \mathrm{GHz}$ of spectral tuning at $780 \mathrm{~nm}$.

Switching the interrogation to telecomm wavelengths (C band, 1530-1560 $\mathrm{nm}$ ) resulted in a reduced transition upon 35 isomerisation - consistent with being much further from the absorption feature. However at this wavelength the copolymer demonstrated greater transparency to the evanescent mode resulting in full guidance along the waveguide with little optical loss. The higher transmitted power along the 40 waveguide resulted in the reflected peak intensity of the Bragg gratings increasing from $6 \mathrm{~dB}$ to $22 \mathrm{~dB}$ above the noise floor, improving the signal-to-noise ratio. The lower loss at $\sim 1550 \mathrm{~nm}$ allowed for the deposition of a thicker film $(719 \pm 23 \mathrm{~nm})$, resulting in a greater evanescent interaction 45 between the waveguide and $\mathbf{6}$, increasing the Bragg shift upon photoisomerisation by over an order of magnitude to $486 \mathrm{pm}$ (Fig. 4). The maximum Bragg shift corresponds to $63 \mathrm{GHz}$ tuning at telecomm wavelengths, sufficiently broad for practical optical tuning within a telecomm channel.

50 By limiting the duration of the UV exposure the cis:trans ratio within the co-polymer can be regulated, allowing fine control of the Bragg wavelength to any value within this half nanometer tuning band. The index change showed the transcis transition is faster than the reverse process, consistent with 55 observations in the time-lapse UV-visible absorption measurements (Fig. 2).

There has been no evidence of degradation of the index change response upon repeated switching of the device during evaluation. However, whilst the cis isomer has long-term 60 instablity at room temperature, with Barley $^{6}$ reporting $\sim 20 \mathrm{~h}$ for a $50 \%$ reconversion, the methacrylate polymer reported here shows a significantly slower linear reconversion over 5 days, with a $50 \%$ reconversion taking $\sim 60 \mathrm{~h}$ at $21{ }^{\circ} \mathrm{C}$.

Investigation into the modal overlap of the transverse ${ }_{65}$ electric (TE) and transverse magnetic (TM) orthogonal optical modes in the presence of the co-polymer overlayer revealed the existence of birefringence. The TE mode penetrates much further from the surface than the TM mode, resulting in a higher sensitivity to changes at the surface. In the presence of 70 the azobenzene-functionalized co-polymer overlayer, this manifested itself as a greater range of tuning than that of the TM mode (Fig. 5). The relative insensitivity of the TM mode could be used for in situ temperature referencing through differential studies of the two modes allowing for the 75 fabrication of an athermal optical device ${ }^{13}$.

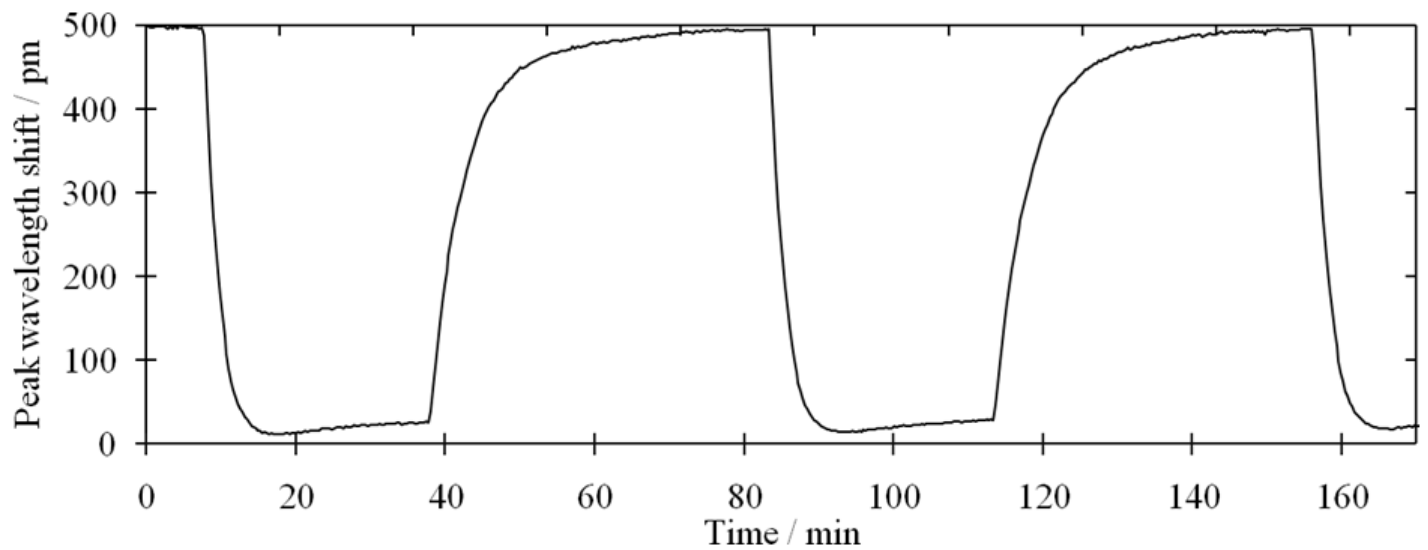

Fig. 4 Reversible photo-switching between the two isomeric states results in a detectable optical Bragg shift of $486 \mathrm{~nm}$ when interrogated at $~ 1550 \mathrm{~nm}$. 

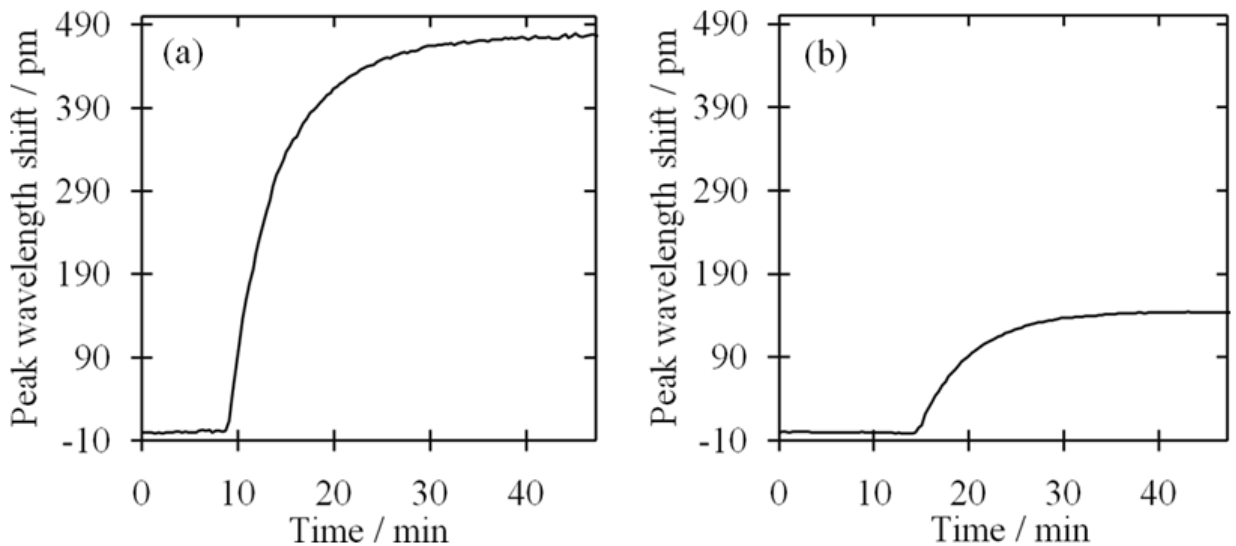

Fig. 5 The transverse electric mode (a) shows a much larger response to the refractive-index change upon photoisomerisation than the transverse magnetic mode (b).

\section{Conclusions}

A $p$-methoxy azobenzene-functionalised methacrylate co5 polymer has been synthesised. This has been shown to undergo reversible photoisomerisation when exposed to UV light, producing a corresponding change in refractive-index. This co-polymer demonstrated high thermal stability to isomerisation, giving rise to applications in passively latched 10 devices. When deposited upon an optical surface a reconfigurable Bragg grating was formed that has the potential for a range of optical applications. In this prototype device the maximum observed tuning was $489 \mathrm{pm}$, corresponding to $63 \mathrm{GHz}$ at telecomm wavelengths. This 15 level of tuning is sufficient for future devices that could find application for wavelength trimming of lasers or for reconfigurable dispersion compensation.

\section{Experimental}

\subsection{General Method.}

${ }_{20}$ Melting points were measured using an Electrothermal melting point apparatus and are uncorrected. Electrospray mass spectra were recorded using a Micromass Platform II single quadrapole mass spectrometer. Nuclear magnetic resonance spectra were collected using either a Bruker AV300 25 spectrometer, or a Bruker DPX400 spectrometer; operating at $400 \mathrm{MHz}$ respectively for ${ }^{1} \mathrm{H} \mathrm{NMR}$ experiments and $100 \mathrm{MHz}$ for ${ }^{13} \mathrm{C}$ and Dept-135 NMR experiments. ${ }^{13} \mathrm{C}$ spectra were collected fully decoupled. Infrared spectra were collected on a Nicolet 380 FT-IR spectrometer with a SmartOrbit Golden ${ }_{30}$ Gate Attenuated Total Reflection (ATR) attachment. Polymer film thickness was measured using a KLA Tencor Alpha-step IQ surface profiler running KLA Alpha-step IQ v2.X. Photoisomerisation was stimulated with a UVP UVGL-25 dual wavelength UV-lamp (4 W, 254/365 nm).

\section{4.2. Optical Interrogation.}

Interrogation of the Bragg grating at $\sim 780 \mathrm{~nm}$ was carried out with a broadband source, generated from a frequency doubled $1550 \mathrm{~nm}$ femtosecond laser source. A $600 \mathrm{~nm}$ band pass filter was used to remove any third harmonic light at $515 \mathrm{~nm}$ that 40 would interfere with photoisomerisation. For interrogation at $\sim 1550 \mathrm{~nm}$ the waveguide was exposed to an Exfo IQ-2300 ASE source as part of an Exfo IQ-203 Optical Test system. The resultant signal was collected by an Ando AQ 6317B optical spectrum analyser (OSA) controlled via a PC running ${ }_{45}$ Labview 8.2.1. Onto this surface a sub-micron film of $6(32.5$ $\mathrm{mg} / \mathrm{mL}$ in 2-butanone) was spun at $1800 \mathrm{rpm}$ for $40 \mathrm{~s}$. The presence of the film and its ability to photoisomerise was confirmed by diffuse-reflectance UV-visible spectroscopy using a Varian Cary 500 Scan UV-VIS-NIR 50 spectrophotometer fitted with an internal DRA 2500 integrating sphere.

\subsection{Materials.}

Commercially available compounds were obtained from Sigma Aldrich or Fisher and, unless specified, all reagents and 55 solvents were reagent grade or better and were used as supplied without further purification.

\subsection{Synthesis.}

\section{4-Phenylazophenol ${ }^{14,15}$ (1a).}

Freshly distilled aniline $(0.50 \mathrm{~mL}, 5.37 \mathrm{mmol})$ was dissolved 60 in a mixture of concentrated hydrochloric acid $(0.50 \mathrm{~mL}, 16.4$ $\mathrm{mmol})$ and water $(5.0 \mathrm{~mL})$. This was cooled $\left(<5^{\circ} \mathrm{C}\right)$ before subsequent dropwise addition of a solution of sodium nitrite $(0.401 \mathrm{~g}, 6.04 \mathrm{mmol})$ in water $(5.0 \mathrm{~mL})$ until an excess was present. This was stirred for 15 minutes, before addition of ${ }_{65}$ phenol $(0.556 \mathrm{~g}, 5.49 \mathrm{mmol})$ in an aqueous solution of sodium hydroxide $(1.0 \mathrm{M}, 2.5 \mathrm{~mL})$. This was stirred for 30 minutes, before filtering, washing with cold water and drying in vacuo to yield an orange solid $(0.755 \mathrm{~g}), 71 \%$ yield. MP: decomposition at $80{ }^{\circ} \mathrm{C}\left(\mathrm{Lit}^{16}: 154{ }^{\circ} \mathrm{C}\right) .{ }^{1} \mathrm{H}$ NMR (MeOD): $\delta$ 706.92 (d, J=8.8 Hz, 2H, Ar-H), 7.37 - 7.56 (m, 4H, Ar-H), 7.76 - $7.88(\mathrm{~m}, \mathrm{~J}=8.8 \mathrm{~Hz}, 4 \mathrm{H}, \mathrm{Ar}-\mathrm{H}) .{ }^{13} \mathrm{C} \mathrm{NMR}(\mathrm{MeOD}): \delta 116.8$ (Ar), 123.50 (Ar), 126.1 (C2,6), 130.2 (Ar), 131.4 (Ar), 147.6 (Ar), 154.2 (Ar), 162.3 (Ar). IR: $v / \mathrm{cm}^{-1} 3300-3100(\mathrm{O}-\mathrm{H})$, 3054 (C-H aromatic), $1602(\mathrm{C}=\mathrm{C}$ aromatic), $1411(\mathrm{~N}=\mathrm{N})$, $751139(\mathrm{C}-\mathrm{N}), 1071(\mathrm{C}-\mathrm{O})$. MS (ES $\left.{ }^{+}, \mathrm{MeOH}\right): \mathrm{m} / \mathrm{z} 198.2(100.0$ $\left.\%,\left[\mathrm{M}^{*}\right]^{+}\right), 199.1\left(95.1 \%,[\mathrm{M}+\mathrm{H}]^{+}\right) . \mathrm{MS}\left(\mathrm{ES}^{-}, \mathrm{MeOH}\right): \mathrm{m} / \mathrm{z}$ $197.2\left(100.0 \%,[\mathrm{M}-\mathrm{H}]^{-}\right)$.

4-(4-Nitrophenyl)azophenol (1b).

$93 \%$ yield. MP: decomposition at $170{ }^{\circ} \mathrm{C}\left(\mathrm{Lit}^{17}: 207{ }^{\circ} \mathrm{C}\right) .{ }^{1} \mathrm{H}$ ${ }_{80} \mathrm{NMR}$ (MeOD): $\delta 6.94(\mathrm{~d}, \mathrm{~J}=9.0 \mathrm{~Hz}, 2 \mathrm{H}, \mathrm{Ar}-\mathrm{H}), 7.87$ (d, J=9.0 
$\mathrm{Hz}, 2 \mathrm{H}, \mathrm{Ar}-\mathrm{H}), 7.97$ (d, J=9.2 Hz, 2H, Ar-H), 8.36 (d, J=9.2 $\mathrm{Hz}, 2 \mathrm{H}, \mathrm{Ar}-\mathrm{H}) . \quad{ }^{13} \mathrm{C}$ NMR (MeOD): $\delta 117.1$ (Ar), 124.2 (C8,12), 125.9 (Ar), 127.0 (Ar), 147.7 (C1), 149.7 (Ar), 157.7 (Ar), 163.7 (Ar). IR: v/cm $3381(\mathrm{O}-\mathrm{H}), 3112$ (C-H aromatic), 5 1584, $1603(\mathrm{C}=\mathrm{C}$ aromatic), $1456(\mathrm{~N}=\mathrm{N}), 1135(\mathrm{C}-\mathrm{N}), 1100$ (C-O). MS $\left(\mathrm{ES}^{+}, \mathrm{MeOH}\right) \mathrm{m} / \mathrm{z} 282.1\left(100.0 \%,[\mathrm{M}+\mathrm{K}]^{+}\right) . \mathrm{MS}$ $\left(\mathrm{ES}^{-}, \mathrm{MeOH}\right) \mathrm{m} / \mathrm{z} 242.2\left(100.0 \%,[\mathrm{M}-\mathrm{H}]^{-}\right)$. 4-(4-Methoxyphenyl)azophenol (1c).

$97 \%$ yield. MP: $132-133{ }^{\circ} \mathrm{C}\left(\mathrm{Lit}^{18}: 149.8^{\circ} \mathrm{C}\right) .{ }^{1} \mathrm{H}$ NMR $10(\mathrm{MeOD}): \delta 3.86\left(\mathrm{~s}, 3 \mathrm{H},-\mathrm{OCH}_{3}\right) 6.90(\mathrm{~d}, \mathrm{~J}=9.0 \mathrm{~Hz}, 2 \mathrm{H}, \mathrm{Ar}-\mathrm{H})$ $7.03(\mathrm{~d}, \mathrm{~J}=9.2 \mathrm{~Hz}, 2 \mathrm{H}, \mathrm{Ar}-\mathrm{H}) 7.76$ (d, J=9.0 Hz, 2H, Ar-H) 7.82 (d, J=9.2 Hz, 2H, Ar-H). ${ }^{13} \mathrm{C}$ NMR (MeOD): $\square \delta 56.2$ (CH3), 115.4 (Ar), 116.8 (Ar), 125.3 (Ar), 125.6 (Ar), 147.7 (Ar), 148.4 (Ar), 161.7 (Ar), 163.3 (Ar). IR: v/cm 3411 (O$\left.{ }_{15} \mathrm{H}\right), 3026$ (C-H aromatic), $2953(\mathrm{C}-\mathrm{H}), 1582,1595(\mathrm{C}=\mathrm{C}$ aromatic), $1436(\mathrm{~N}=\mathrm{N}), 1149(\mathrm{C}-\mathrm{N}), 1014(\mathrm{C}-\mathrm{O}) . \quad \mathrm{MS}\left(\mathrm{ES}^{-}\right.$, $\mathrm{MeOH}): \mathrm{m} / \mathrm{z} 227.2\left(100.0 \%,[\mathrm{M}-\mathrm{H}]^{-}\right)$.

Ethyl (4-phenylazophenoxyacetate) ${ }^{19}$ (2a).

4-Phenylazophenol (1a, $0.380 \mathrm{~g}, 1.90 \mathrm{mmol}$ ) was dissolved in 20 acetone (silica dried, $60 \mathrm{~mL}$ ), followed by potassium carbonate $(1.658 \mathrm{~g}, 11.9 \mathrm{mmol})$ and the mixture was warmed until everything dissolved. To this stirred solution, ethyl bromoacetate $(0.125 \mathrm{~mL}, 3.75 \mathrm{mmol})$ and sodium iodide (0.287 g, $1.9 \mathrm{mmol}$, in $4.0 \mathrm{~mL}$ acetone) were then added. The

25 reaction mixture was heated under reflux for $16 \mathrm{~h}$. The solvent was removed in vacuo to give an orange solid. This was subsequently extracted into diethyl ether $(3 \mathrm{x} 40 \mathrm{~mL})$ from water $(40 \mathrm{~mL})$; before drying with magnesium sulphate, filtering and removing the solvent in vacuo. The resultant 30 solid was purified by column chromatography (50/50 diethyl ether/light petroleum (40-60)) to give an orange solid (0.307 g), $90 \%$ yield. MP: $66{ }^{\circ} \mathrm{C}\left(\mathrm{Lit}^{20}: 70{ }^{\circ} \mathrm{C}\right) .{ }^{1} \mathrm{H}$ NMR (MeOD): $\delta 1.26\left(\mathrm{t}, \mathrm{J}=7.1 \mathrm{~Hz}, 3 \mathrm{H},-\mathrm{CH}_{3}\right), 4.23(\mathrm{q}, \mathrm{J}=7.1 \mathrm{~Hz}, 2 \mathrm{H}$, $\left.\mathrm{OCH}_{2}\right), 4.77\left(\mathrm{~s}, 2 \mathrm{H},-\mathrm{OCH}_{2} \mathrm{C}(\mathrm{O})\right), 7.05(\mathrm{~d}, \mathrm{~J}=9.0 \mathrm{~Hz}, 2 \mathrm{H}, \mathrm{Ar}-$ $\left.{ }_{35} \mathrm{H}\right), 7.39-7.53(\mathrm{~m}, \mathrm{~J}=7.5 \mathrm{~Hz}, 3 \mathrm{H}, \mathrm{Ar}-\mathrm{H}), 7.83$ (dd, J=8.2, 1.7 $\mathrm{Hz}, 2 \mathrm{H}, \mathrm{Ar}-\mathrm{H}), 7.87$ (d, J=9.2Hz, 2H, Ar-H). 13C NMR (MeOD): $\delta 14.6$ (CH3), $62.6(\mathrm{CH} 2), 66.4(\mathrm{CH} 2), 116.2$ (Ar), 123.7 (Ar), 125.8 (Ar), 130.3 (Ar), 131.9 (Ar), 148.9 (Ar), 154.17 (Ar), 162.1 (Ar), $170.6(\mathrm{C}(\mathrm{O}))$. IR: v/cm $\mathrm{cm}^{-1} 3068(\mathrm{C}-\mathrm{H}$ 40 aromatic), $2937(\mathrm{C}-\mathrm{H}), 1726(\mathrm{C}=\mathrm{O}), 1600(\mathrm{C}=\mathrm{C}$ aromatic), $1495(\mathrm{~N}=\mathrm{N}), 1149(\mathrm{C}-\mathrm{N}), 1077(\mathrm{C}-\mathrm{O}) . \mathrm{MS}\left(\mathrm{ES}^{+}, \mathrm{MeOH}\right) \mathrm{m} / \mathrm{z}$ $285.2\left(14.5 \%,[\mathrm{M}+\mathrm{H}]^{+}\right), 307.1\left(64.4 \%,[\mathrm{M}+\mathrm{Na}]^{+}\right)$.

Ethyl (4-(4-nitrophenyl)azophenoxyacetate) (2b).

$45 \%$ yield. MP: $138-139{ }^{\circ} \mathrm{C}\left(\mathrm{Lit}^{21}: 150.5^{\circ} \mathrm{C}\right) .{ }^{1} \mathrm{H}$ NMR ${ }_{45}\left(\mathrm{CDCl}_{3}\right): \delta 1.33\left(\mathrm{t}, \mathrm{J}=7.1 \mathrm{~Hz}, 3 \mathrm{H},-\mathrm{CH}_{3}\right), 4.32(\mathrm{q}, \mathrm{J}=7.0 \mathrm{~Hz}$, $\left.2 \mathrm{H},-\mathrm{OCH}_{2}\right), 4.74\left(\mathrm{~s}, 2 \mathrm{H},-\mathrm{OCH}_{2} \mathrm{C}(\mathrm{O})\right), 7.06(\mathrm{~d}, \mathrm{~J}=9.0 \mathrm{~Hz}, 2 \mathrm{H}$, Ar-H), 7.98 (d, J=9.2 Hz, 2H, Ar-H), 8.01 (d, J=9.0 Hz, 2H, $\mathrm{Ar}-\mathrm{H}), 8.38$ (d, J=9.0 Hz, 2H, Ar-H). ${ }^{13} \mathrm{C} \mathrm{NMR} \mathrm{(CDCl3):} \delta$ $14.1\left(\mathrm{CH}_{3}\right), 61.6\left(\mathrm{CH}_{2}\right), 65.4\left(\mathrm{CH}_{2}\right), 115.1(\mathrm{Ar}), 123.2(\mathrm{Ar})$, 50124.7 (Ar), 125.1 (Ar), 125.5 (Ar), 147.5 (Ar), 148.3 (Ar), 155.9 (Ar), $161.2(\mathrm{Ar}), 168.2(\mathrm{C}(\mathrm{O}))$. IR: $\mathrm{v} / \mathrm{cm}^{-1} 2897,3107$ (C-H aromatic), 2909 ([C]C-H), 2847 ([O]C-H), 1755 (C=O), 1585, 1601 (C=C aromatic), $1499(\mathrm{~N}=\mathrm{N}), 1140(\mathrm{C}-\mathrm{N}), 1082$ (C-O). MS (ES, $\mathrm{MeOH}): \mathrm{m} / \mathrm{z} 352.2\left(98.5 \%,[\mathrm{M}+\mathrm{Na}]^{+}\right)$, ${ }_{55} 681.4\left(100.0 \%,[2 \mathrm{M}+\mathrm{Na}]^{+}\right)$. HRMS $\left(\mathrm{ES}^{+}, \mathrm{MeOH}\right)$ calcd for $\mathrm{C}_{16} \mathrm{H}_{15} \mathrm{~N}_{3} \mathrm{O}_{5} \mathrm{Na}[\mathrm{M}+\mathrm{Na}]^{++}$352.0904, found 352.0910.

Ethyl (4-(4-methoxyphenyl)azophenoxyacetate) (2c). $53 \%$ yield. MP: $103-105{ }^{\circ} \mathrm{C} .{ }^{1} \mathrm{H}$ NMR $\left(\mathrm{CDCl}_{3}\right): \delta 1.32(\mathrm{t}, \mathrm{J}$ $\left.=7.2 \mathrm{~Hz}, 3 \mathrm{H},-\mathrm{CH}_{3}\right), 3.89\left(\mathrm{~s}, 3 \mathrm{H},-\mathrm{OCH}_{3}\right), 4.30(\mathrm{q}, \mathrm{J}=7.1 \mathrm{~Hz}$, $\left.{ }_{60} 2 \mathrm{H},-\mathrm{OCH}_{2}\right), 4.70\left(\mathrm{~s}, 2 \mathrm{H},-\mathrm{OCH}_{2} \mathrm{C}(\mathrm{O})\right), 7.02(\mathrm{dd}, \mathrm{J}=9.1,2.8$ $\mathrm{Hz}, 4 \mathrm{H}, \mathrm{Ar}-\mathrm{H}), 7.89(\mathrm{dd}, \mathrm{J}=9.1,1.4 \mathrm{~Hz}, 4 \mathrm{H}, \mathrm{Ar}-\mathrm{H}) .{ }^{13} \mathrm{C}$ NMR $\left(\mathrm{CDCl}_{3}\right): \delta 14.2\left(\mathrm{CH}_{3}\right), 55.5\left(\mathrm{CH}_{3}\right), 61.5\left(\mathrm{CH}_{2}\right), 65.5$ $\left(\mathrm{CH}_{2}\right), 114.2$ (Ar), 114.9 (Ar), 124.3 (Ar), 124.4 (Ar), 147.0 (Ar), 147.7 (Ar), 159.6 (Ar), 161.7 (Ar), 168.5 (C(O)). IR: 65 v/cm-1 3069 (C-H aromatic), 2937, 2977 (C-H), 1758 (C=O), 1579, $1599(\mathrm{C}=\mathrm{C}$ aromatic), $1437(\mathrm{~N}=\mathrm{N}), 1149(\mathrm{C}-\mathrm{N}), 1027$ (C-O). MS (ES $\left.{ }^{+}, \mathrm{MeOH}, \mathrm{m} / \mathrm{z}\right): 315.2\left(100.0 \%,[\mathrm{M}+\mathrm{H}]^{+}\right)$, $337.2\left(55.9 \%,[\mathrm{M}+\mathrm{Na}]^{+}\right)$. HRMS $\left(\mathrm{ES}^{+}, \mathrm{MeOH}\right)$ calcd for $\mathrm{C}_{17} \mathrm{H}_{19} \mathrm{~N}_{2} \mathrm{O}_{4}[\mathrm{M}+\mathrm{H}]^{+}$315.1339, found 315.1343, calcd for ${ }_{70} \mathrm{C}_{17} \mathrm{H}_{18} \mathrm{~N}_{2} \mathrm{O}_{4} \mathrm{Na}[\mathrm{M}+\mathrm{Na}]^{+}$337.1159, found 337.1155.

4-Phenylazophenoxyacetic acid ${ }^{21}(3 a)$.

Ethyl (4-phenylazophenoxyacetate) (2a, $0.280 \mathrm{~g}, 0.971 \mathrm{mmol})$ was dissolved in ethanol $(40 \mathrm{~mL})$. To this, an aqueous solution of sodium hydroxide $(0.056 \mathrm{M}, 40 \mathrm{~mL})$ was added 75 before heating the mixture under reflux for 3 hours. The reaction mixture was acidified (conc. $\mathrm{HCl}$ ) before it was extracted with diethyl ether $(3 \times 60 \mathrm{~mL})$. The combined extracts were dried with magnesium sulfate, filtered and the solvent was removed in vacuo to yield a yellow solid $(0.255$ $80 \mathrm{~g}),>99 \%$ yield. MP: $180{ }^{\circ} \mathrm{C}\left(\mathrm{Lit}^{21}: 184{ }^{\circ} \mathrm{C}\right) .{ }^{1} \mathrm{H}$ NMR (MeOD) $\delta 4.72\left(\mathrm{~s}, 2 \mathrm{H},-\mathrm{OCH}_{2} \mathrm{C}(\mathrm{O})\right), 7.04(\mathrm{~d}, \mathrm{~J}=9.0 \mathrm{~Hz}, 2 \mathrm{H}$, Ar-H), 7.37 - 7.54 (m, $3 \mathrm{H}, \mathrm{Ar}-\mathrm{H}), 7.81$ (dd, J=8.1, $1.37 \mathrm{~Hz}$, 2H, Ar-H), 7.87 (d, J=9.0 Hz, 2H, Ar-H). ${ }^{13} \mathrm{C}$ NMR (MeOD) $\delta 66.1\left(\mathrm{CH}_{2}\right), 116.2(\mathrm{Ar}), 123.7(\mathrm{Ar}), 125.8(\mathrm{Ar}), 130.3(\mathrm{Ar})$, 85131.9 (Ar), 148.8 (Ar), 154.2 (Ar), 162.1 (Ar) 172.3 (C(O)). IR: v/cm ${ }^{-1} 3068$ (C-H aromatic), $2915(\mathrm{C}-\mathrm{H}), 2700$ broad (O$\mathrm{H}), 1706(\mathrm{C}=\mathrm{O}), 1602,1582(\mathrm{C}=\mathrm{C}$ aromatic $), 1501(\mathrm{~N}=\mathrm{N})$, 1143 (C-N), 1085 (C-O). MS (ES $\left.{ }^{+}, \mathrm{MeOH}\right) \mathrm{m} / \mathrm{z} 257.1$ (67.9 $\left.\%[\mathrm{M}+\mathrm{H}]^{+}\right), 279.1\left(95.2 \%,[\mathrm{M}+\mathrm{Na}]^{+}\right), 311.1(100.0 \%$, $\left.90[\mathrm{M}+\mathrm{Na}+\mathrm{MeOH}]^{+}\right) . \quad \mathrm{UV}$-vis $(\mathrm{MeOH}): \lambda_{\max } / \mathrm{nm} \quad 320.5,450.5$ (cis), 342.0 (trans). HRMS (ES $\left.{ }^{+}, \mathrm{MeOH}\right)$ calcd for $\mathrm{C}_{14} \mathrm{H}_{13} \mathrm{~N}_{2} \mathrm{O}_{3}[\mathrm{M}+\mathrm{H}]^{+}$257.0921, found 257.0918, calcd for $\mathrm{C}_{14} \mathrm{H}_{12} \mathrm{~N}_{2} \mathrm{O}_{3} \mathrm{Na}[\mathrm{M}+\mathrm{Na}]^{+} 279.0740$, found 279.0737.

4-(4-Nitrophenyl)azophenoxyacetic acid $^{21}$ (3b).

$95>99 \%$ yield. MP: decomposed at $175^{\circ} \mathrm{C}\left(\mathrm{Lit}^{21}: 236^{\circ} \mathrm{C}\right) .{ }^{1} \mathrm{H}$ NMR (MeOD): $\delta 4.75$ (s, 2H, $\left.-\mathrm{OCH}_{2} \mathrm{C}(\mathrm{O})\right), 7.09$ (d, J=9.0 Hz, 2H, Ar-H), 7.97 (d, J=9.2 Hz, 2H, Ar-H), 8.00 (d, J=9.0 Hz, $2 \mathrm{H}, \mathrm{Ar}-\mathrm{H}), 8.37$ (d, J=9.2 Hz, $2 \mathrm{H}, \mathrm{Ar}-\mathrm{H}) .{ }^{13} \mathrm{C}$ NMR (MeOD) $\delta \mathrm{d} 72.00\left(\mathrm{CH}_{2}\right), 116.0(\mathrm{Ar}), 124.0(\mathrm{Ar}), 125.6(\mathrm{Ar}), 126.3$ 100 (Ar), 142.6 (Ar, 149.1 (Ar), 157.2 (Ar) 159.0 (Ar), 179.7 (C(O)). IRQ:v/cm ${ }^{-1} 3108(\mathrm{C}-\mathrm{H}$ aromatic), $2912(\mathrm{C}-\mathrm{H}), 2845$ ([O]C-H), $1704(\mathrm{C}=\mathrm{O}), 1580,1600(\mathrm{C}=\mathrm{C}$ aromatic), 1496 $(\mathrm{N}=\mathrm{N}), 1138$ (C-N), $1070(\mathrm{C}-\mathrm{O}) . \quad \mathrm{MS}\left(\mathrm{ES}^{+}, \mathrm{MeOH}\right): \mathrm{m} / \mathrm{z}$ $301.2\left(30.6 \%[\mathrm{M}]^{*+}\right), 302.3\left(6.7 \%[\mathrm{M}+\mathrm{H}]^{+}\right), 324.2(9.3 \%$, $\left.105[\mathrm{M}+\mathrm{Na}]^{+}\right), 333.3\left(5.6 \% \quad[\mathrm{M}+\mathrm{MeOH}]^{\bullet+}\right), 356.1 \quad(9.3 \%$, $\left.[\mathrm{M}+\mathrm{Na}+\mathrm{MeOH}]^{+}\right) . \mathrm{MS}\left(\mathrm{ES}^{-}, \mathrm{MeOH}\right): \mathrm{m} / \mathrm{z} 300.1(16.3 \%,[\mathrm{M}-$ $\mathrm{H}^{-}$). UV-vis $(\mathrm{MeOH}): \lambda_{\max } / \mathrm{nm} 367.5$ (cis), 370.0 (trans). HRMS $\left(\mathrm{ES}^{+}, \mathrm{MeOH}\right)$ calcd for $\mathrm{C}_{14} \mathrm{H}_{12} \mathrm{~N}_{3} \mathrm{O}_{5}[\mathrm{M}+\mathrm{H}]^{+} 302.0771$, found 302.0766 .

110 4-(4-Methoxyphenyl)azophenoxyacetic acid (3c).

$>99 \%$ yield. MP: $182-183{ }^{\circ} \mathrm{C} .{ }^{1} \mathrm{H}$ NMR $\left(\right.$ DMSO- $\left.d_{6}\right): \delta 3.85$ $\left(\mathrm{s}, 3 \mathrm{H},-\mathrm{OCH}_{3}\right) 4.79\left(\mathrm{~s}, 2 \mathrm{H},-\mathrm{OCH}_{2} \mathrm{C}(\mathrm{O})\right), 7.09(\mathrm{~d}, \mathrm{~J}=9.0 \mathrm{~Hz}$, 2H, Ar-H) $7.10(\mathrm{~d}, \mathrm{~J}=9.0 \mathrm{~Hz}, 2 \mathrm{H}, \mathrm{Ar}-\mathrm{H}) 7.83(\mathrm{~d}, \mathrm{~J}=9.0 \mathrm{~Hz}$, $2 \mathrm{H}, \mathrm{Ar}-\mathrm{H}) 7.84(\mathrm{~d}, \mathrm{~J}=9.0 \mathrm{~Hz}, 2 \mathrm{H} \mathrm{Ar}-\mathrm{H}) .{ }^{13} \mathrm{C}$ NMR (DMSO$\left.{ }_{115} d_{6}\right) \delta 55.6\left(\mathrm{OCH}_{3}\right), 64.8\left(\mathrm{CH}_{2}\right), 114.6(\mathrm{Ar}), 115.1(\mathrm{Ar}), 124.1$ (Ar), 124.2 (Ar), 146.3 (Ar), 146.6 (Ar), 160.0 (Ar), 161.6 (Ar), $169.9(\mathrm{C}(\mathrm{O}))$. IR: v/cm ${ }^{-1}$ 3419, $3515(\mathrm{O}-\mathrm{H}), 2998(\mathrm{C}-\mathrm{H}$ aromatic), $2972(\mathrm{C}-\mathrm{H}), 1704(\mathrm{C}=\mathrm{O}), 1579,(\mathrm{C}=\mathrm{C}$ aromatic $)$, 
$1437(\mathrm{~N}=\mathrm{N}), 1144(\mathrm{C}-\mathrm{N}), 1018(\mathrm{C}-\mathrm{O}) . \mathrm{MS}\left(\mathrm{ES}^{+}, \mathrm{MeOH}\right): \mathrm{m} / \mathrm{z}$ $287.2\left(16.9 \%[\mathrm{M}+\mathrm{H}]^{+}\right), 309.2\left(25.7 \%,[\mathrm{M}+\mathrm{Na}]^{+}\right), 341.2$

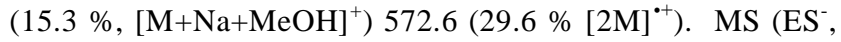
$\mathrm{MeOH}) \mathrm{m} / \mathrm{z} 285.2\left(18.3 \%,[\mathrm{M}-\mathrm{H}]^{-}\right)$. UV-vis $(\mathrm{MeOH})$ ${ }_{5} \lambda_{\max } / \mathrm{nm} 444.0$ (cis), 356.0 (trans). HRMS (ES $\left.{ }^{+}, \mathrm{MeOH}\right)$ calcd for $\mathrm{C}_{15} \mathrm{H}_{15} \mathrm{~N}_{2} \mathrm{O}_{4}[\mathrm{M}+\mathrm{H}]^{+}$287.1026, found 287.1027.

4-(4-Methoxyphenyl)azophenoxyacetyl chloride ${ }^{22}$ (4).

4-(4-Methoxyphenyl)azophenoxyacetic acid (3c, $0.110 \mathrm{~g}$, $0.359 \mathrm{mmol})$ was refluxed in thionyl chloride $(5 \mathrm{~mL}, 68.5$ $10 \mathrm{mmol}$ ) overnight under nitrogen. The remaining thionyl chloride was removed by distillation under vacuum $\left(50{ }^{\circ} \mathrm{C}\right)$, before drying the red solid under vacuum (assumed quantitative yield and used immediately without further purification). MP: $164-165^{\circ} \mathrm{C}$. MS $\left(\mathrm{ES}^{+}, \mathrm{MeOH}\right): \mathrm{m} / \mathrm{z}$ $15323.2\left(100.0 \%,[\mathrm{~N}+\mathrm{Na}]^{+}\right), \mathrm{N}$ represents the molecular ion for methyl [4-(4-methoxyphenyl)azophenoxyacetate] formed from the reaction of ${ }^{4}$ with the methanol MS solvent. The formation of the methyl ester was not seen with samples of $\mathbf{3 c}$ and as such can be used as an indicator for successful 20 synthesis of 4.

Poly(methyl methacrylate)(hydroxyethyl methacrylate), P(MMA)(HEMA) (49:51) ${ }^{11}$ (5).

A mixture of methyl methacrylate (MMA, $0.89 \mathrm{~mL}, 8.3$ mmol) and hydroxyethyl methacrylate (HEMA, $0.94 \mathrm{~mL}, 7.5$ $25 \mathrm{mmol})$ was dissolved in methanol $(6.0 \mathrm{~mL})$ under a slow stream of nitrogen at $60{ }^{\circ} \mathrm{C}$ for 30 minutes prior to the addition of azobisisobutyronitrile (AIBN, $51.3 \mathrm{mg}, 0.316$ mmol). The reaction was then stirred overnight before heating at $60{ }^{\circ} \mathrm{C}$ for 24 hours. The viscous solution was 30 poured into diethyl ether $(200 \mathrm{~mL})$ to yield a white precipitate. The cloudy solution was centrifuged before decanting the eleuent. The solid was redissolved in methanol and precipitated from diethyl ether a further two times, before drying the white solid under vacuum $(1.5857 \mathrm{~g}), 88 \%$ yield.

${ }_{35}{ }^{1} \mathrm{H}$ NMR (MeOD): $\delta 0.92$ and 1.10 (br.s., 6H, $-\mathrm{CH}_{3}$ ), 1.96 (br.s., $\left.4 \mathrm{H},-\mathrm{CH}_{2}\right) 3.65$ (br.s., $\left.3 \mathrm{H},-\mathrm{OCH}_{3}\right) 3.80$ and 4.07 (br.s., $\left.2 \mathrm{H},-\mathrm{CH}_{2} \mathrm{CH}_{2-}\right) .{ }^{13} \mathrm{C}$ NMR (DMSO-d $\left.d_{6}\right): \delta 16.2\left(\mathrm{CH}_{3}\right), 18.5$ $\left(\mathrm{CH}_{3}\right), 44.0(\mathrm{C} \alpha), 44.3(\mathrm{C} \alpha), 51.6\left(\mathrm{OCH}_{3}\right), 53.6\left({\left.\mathrm{C} \beta \mathrm{H}_{2}\right), 58.5}^{2}\right.$ $\left(\mathrm{CH}_{2} \mathrm{OH}\right), 66.3\left(\mathrm{OCH}_{2}\right), 176.3(\mathrm{C}(\mathrm{O})), 177.3(\mathrm{C}(\mathrm{O})) . \quad \mathrm{IR}$ : $40 \mathrm{v} / \mathrm{cm}^{-1} 3500$ (broad, O-H), 2991 (C-H), 2948 (C-H), 1716 $(\mathrm{C}=\mathrm{O})$. UV-vis $(\mathrm{MeOH}): \lambda_{\max } / \mathrm{nm} 215$. GPC $\left(\mathrm{M}_{\mathrm{w}}\right.$, expressed as 'PMMA equivalent' molecular weight) 190,500.

Poly(methyl methacrylate) (hydroxyethyl methacrylate)(4-(4methoxyphenyl) azophenoxyacetylethyl methacrylate), ${ }_{45}$ P(MMA)(HEMA)(Azo-HEMA) (49:46:5) (6).

P(MMA)(HEMA) (5, $1.005 \mathrm{~g}, 7.72 \mathrm{mmol}$ of HEMA) was dissolved in 2-butanone $(12.0 \mathrm{~mL})$ under a slow stream of nitrogen followed by triethylamine (TEA, $1.89 \mathrm{~mL} .14 \mathrm{mmol}$ ) to give a colourless solution. 4-(4${ }_{50}$ Methoxyphenyl)azophenoxyacetyl chloride $(4,0.401 \mathrm{~g}, 1.4$ mmol) was dissolved in 2-butanone $(4.0 \mathrm{~mL})$ to give an orange solution, before adding to the stirred polymer solution, instantaneously forming an orange precipitate. After stirring for 36 hours the viscous solution was poured into diethyl ether $55(150 \mathrm{~mL})$ to yield a caramel precipitate. This was centrifuged and decanted before trituration in water $(50 \mathrm{~mL})$ to leave an orange solid. This was dissolved in 2-butanone $(150 \mathrm{~mL})$, centrifuged and precipitated from diethyl ether a further two times. The resultant orange solid was dried under vacuum
${ }_{60}(0.8366 \mathrm{~g}), 62 \%$ yield. ${ }^{1} \mathrm{H}$ NMR (DMSO- $\left.d_{6}\right): \delta 0.76$ and 0.90 (br.s., 4.26H, $-\mathrm{CH}_{3}$ ), 1.78 (br.s., $1.98 \mathrm{H},-\mathrm{CH}_{2}$ ) 3.53 (br.s., $\left.3.0 \mathrm{H},-\mathrm{OCH}_{3},-\mathrm{CH}_{2} \mathrm{CH}_{2}-\right) 3.90$ (br.s., $1.30 \mathrm{H},-\mathrm{CH}_{2} \mathrm{CH}_{2}$ ) $), 4.80$ (br.s., 0.54H, -OH) 7.12 (br.s., 0.25H, Ar-H) 7.85 (br.s., $0.25 \mathrm{H}, \mathrm{Ar}-\mathrm{H}) .{ }^{13} \mathrm{C}$ NMR (DMSO- $\left.d_{6}\right): \delta 16.21\left(\mathrm{CH}_{3}\right), 18.3$ $65\left(\mathrm{CH}_{3}\right), 44.0(\mathrm{C} \alpha), 44.3(\mathrm{C} \alpha), 51.6\left(\mathrm{OCH}_{3}\right), 53.5\left({\left.\mathrm{C} \beta \mathrm{H}_{2}\right), 55.6}\right.$ ((Azo) $\left.\mathrm{OCH}_{3}\right), 58.5\left(\mathrm{CH}_{2} \mathrm{OH}\right), 66.3\left(\mathrm{OCH}_{2}\right), 114.5((\mathrm{Azo})$ Ar), 115.1 ((Azo) Ar), 124.0 ((Azo) Ar), 124.2 ((Azo) Ar), 161.6 ((Azo) C(O)), $176.3(\mathrm{C}(\mathrm{O})), 177.0(\mathrm{C}(\mathrm{O}))$. IR: $v / \mathrm{cm}^{-1}$ 3500 (broad, weak O-H), 2992 (C-H), 2949 (C-H), 1718 $70(\mathrm{C}=\mathrm{O}), 1598(\mathrm{C}=\mathrm{C})$. UV-vis (2-butanone): $\lambda_{\max } / \mathrm{nm} 356,447$. GPC $\left(\mathrm{M}_{\mathrm{w}}\right.$, expressed as 'PMMA equivalent' molecular weight) 301,500 .

\section{References}

1 M. Sun, W. Que and X. J. Hu, J. Sol-Gel. Sci. Technol., 2009, 50, $75 \quad 415-420$.

2 P. S. Ramanujam, S. Hvilsted, F. Ujhelyi, P. Koppa, E. Lörincz, G. Erdei and G. Szarvas, Synth. Met., 2001, 124, 145-150.

3 H. Rau, Angew. Chem. Int. Ed., 1973, 12, 224-235.

4 H. G. Limberger, N. Hong Ky, D. M. Costantini, R. P. Salathe, C. A.

80 P. Muller, and G. R. Fox, IEEE Photon. Technol. Lett., 1998, 10, 361-363.

5 S. Y. Kim, S. B. Lee, S. W. Kwon, S. S. Choi and J. Jeong, Electron. Lett., 1998, 34, 104-105.

6 L. Cruz, A. Diez, M. V. Andrés, A. Segura, B. Ortega, and L. Dong,

85 Electron. Lett., 1997, 33, 235-236.

7 M. Le Blanc, S. Y. Huang, M. M. Ohn and R. M. Measures, Electron. Lett., 1994, 30, 2163-2165.

8 M. Olivero and M. Svalgaard, Optics Express, 2005, 13, 8390-8399.

9 D. O. Kundys, J. C. Gates, S. Dasgupta, C. B. E. Gawith and P. G. R. 90 Smith, IEEE Photon Technol. Lett., 2009, 21, 947-949.

10 G. D. Emmerson, S. P. Watts, C. B. E. Gawith, V. Albanis, M. Ibsen, R. B. Williams and P. G. R. Smith,. Electron. Lett., 2002, 38, 1531-1532.

11 S. H. Barley, A. Gilbert and G. R. Mitchell, J. Mater. Chem., 1991, 1, 481-482.

12 J-S. Koo, P. G. R. Smith, R.B. Williams, M. C. Grossel and M. J. Whitcombe, Chem. Mater., 2002, 14, 5030-5036.

13 R. M. Parker, J. C. Gates, M. C. Grossel, and P. G. R. Smith, Sensors \& Actuators: B. Chemical, 2010, 145, 428-432.

10014 M. Odabaşoğlu, G. Turgut and H. Kocaokutgen, Phosphorus, Sulfur, and Silicon and the Related Elements, 1999, 152, 27-34.

15 A. Ault, Techniques and experiments for organic chemistry, University Science Books, 4th edn., 1976.

16 H. Iwamoto, M. Yoshimura, T. Sonoda and H. Kobayashi, Bull. Chem. Soc. Jpn., 1983, 56, 796-801.

17 M. L. Rahman, C. Tschierske, M. Yusoff, and S. Silong, Tetrahedron Lett., 2005, 46, 2303-2306.

18 J. Kim and M. Novak, Macromolecules, 2004, 37, 8286-8292.

19 D. Jackson, Ph.D. Thesis, University of Southampton, 2008.

11020 E. Woolfolke, L. W. Naldson and M. Payne, J. Org. Chem., 1962, 27, 2653-2654.

21 V. Ettel and J. Myska, Collect. Czech. Comm. Commun., 1958, 23, 1341-1344.

22 J. A. Mills, J. Chem. Soc., 1951, 2332-2334. 